\title{
Welding Process Automation of Aluminum Alloys for the Transport Industry: An Industrial Robotics Approach
}

\author{
João Ribeiro ${ }^{1(\bowtie)}$, José Gonçalves ${ }^{2}$, and Nuno Mineiro ${ }^{3}$ \\ 1 CIMO and Instituto Politécnico de Bragança, Campus de Santa Apolónia, \\ 5300-253 Bragança, Portugal

\begin{abstract}
The materials used in the transport industry have been changing in the last decades. The traditional and heavy steel have been switching by the light alloys like aluminum alloys. However, despite their advantages as low density and high corrosion resistance, the manufacturing process, especially fusion welding, is very demanding and challenging. In the transport industry, most of the hyperstatic components made in aluminum alloys are welded manually with the associate financial costs as well as the lack of quality and repeatability. For these reasons, it is urgent to develop new methodologies to automate this process. The present work intends to show a scientific method to automate the welding process of hyperstatic frames, very common in bicycles, made in aluminum alloy. This methodology involves two steps, the first one in which is performed numerical simulations to determine the optimal welding parameters to minimize the distortion and residual stresses. The second step is experimental one, and it is created an automated welding cell with a robot to weld the frames. It has been proved that it is possible to obtain welding aluminum frames with acceptable quality in agreement with the ASME IX standard.
\end{abstract}

Keywords: Automation $\cdot$ Robotic $\cdot$ Welding $\cdot$ Numerical simulation $\cdot$ Optimization · Aluminum alloys

\section{Introduction}

The transport industry is one of the most critical sectors in the global economy, and any change in this sector has an impact on the costs of virtually all other economic areas. Due to the ever-higher energy prices and progressively more restrictive environmental requirements, there was a need, on the part of this industry, to adapt to a new reality. Thus, the different sectors of the transport industry have been adapted to the new requirements,

(C) The Editor(s) (if applicable) and The Author(s), under exclusive license to Springer Nature Switzerland AG 2021

J. A. Gonçalves et al. (Eds.): CONTROLO 2020, LNEE 695, pp. 72-81, 2021.

https://doi.org/10.1007/978-3-030-58653-9_7 
at different levels, ranging from the development of more efficient propulsion systems, commonly known as engines [1, 2] to the selection of lighter materials [3, 4].

The use of aluminum alloys in the transport industry has been growing, particularly in the light and heavy automotive industry, both in terms of structure [5] and sheet metal components [6]. According to the European Aluminum Association, the replacement of steel by aluminum alloys in vehicles allowed a $30 \%$ saving in energy consumption and a significant reduction in $\mathrm{CO} 2$ emissions [7], this material also has the advantage of being fully recycled. Due to their low density and resistance to corrosion, these materials are also widely used in non-motorized vehicles, namely in bicycles [8] and whose use has grown significantly [9]. Despite all the listed advantages of aluminum alloys, there are some disadvantages compared to iron-carbonic alloys, namely the higher price, more demanding manufacturing processes in terms of quality control [10], more difficult welding junction processes [11, 12] and a lower fatigue life [13]. In the case of the transport industry, these limitations are more significant when welding structural elements such as chassis or bicycle frames. These elements correspond to hyperstatic structures with high rigidity that, associated with the residual stresses generated during the welding process, may cause cracking [14] or distortion of the structure $[5,14]$ and, in the case of no cracking or distortions, the level of residual stresses is so high that it will significantly decrease the fatigue life of these structures $[15,16]$.

Specific characteristics intrinsic to aluminum introduce difficulties for welding. The most important of these corresponds to the formation of a surface oxide layer, resulting from the reaction of aluminum with atmospheric oxygen. This film protects the metal against corrosion, but it also has a considerably higher melting point than the original $\mathrm{Al}$ element. Consequently, successful welding depends, in part, on the technique applied for the disintegration of this oxide layer, which will remain stable even after the melting of the aluminum [17].

In the case of MIG welding, the flow of the shielding gas over the consumable electrode removes the oxide from the melting bath. However, there are other essential limitations in the welding process for aluminum alloys used in the manufacture of hyperstatic structures, the most relevant is the susceptibility to cracking in welding [17], the distortions and thermally induced stresses and post-weld heat treatment.

Despite the difficulties mentioned above, it is possible to weld hyperstatic structures in aluminum alloys with conventional techniques (MIG or TIG), as long as chosen the appropriate welding parameters, the correct joint preparation, the fixation of the elements to be welded with the degree of adjusted stiffness and a welding sequence that limits distortion and residual stresses $[18,19]$. However, it is only possible to accommodate all these parameters during the welding process; so, it is necessary to adjust and balance some of these elements. In contrast, welding is being carried out and, as such, requires that these processes be manual and depend on the qualification and sensitivity of the welder. Therefore, it is challenging to automate this process; accordingly, there is a need for an in-depth study and development for the automation of welding systems for hyperstatics structures made of aluminum alloys.

The proposed approach to overcome the limitations of automated or robotic welding to weld hyperstatic aluminum alloy structures will be carried out in two distinct phases: numerical simulation using finite element programs dedicated to welding and 
experimental tests with a welding robot based on an optimization method, Taguchi, to determine the optimal welding parameters for the type of welding under analysis.

\section{Numerical Simulation}

In the last decades, numerical simulation methods have been progressively replacing the performance of experimental tests in several manufacturing processes [20-23], which have higher costs and the time to prepare and perform the tests. Much higher than the computation time required to simulate the behavior of processed materials. In the case of welds, simulations must foresee distortions [23], residual stresses [24], and, in some cases, changes in the microstructure of the weld bead [25]. In these simulations, it is necessary to define the geometry of the elements to be connected, the welded materials, the welding parameters (current, voltage, travel speed, contact-to-work-distance), and the rigidity degree of the element's fixation.

In this work was implemented a preliminary numerical simulation to minimize the residual stresses in welding of 6082-T6 aluminum alloy. To reach this goal, the Taguchi optimization method was used, determining which combination of parameters minimizes the residual stresses in the 6082-T6 aluminum alloy. The welding parameters selected were the welding current, the torch angle, and the welding travel speed. For each parameter, three levels were used, combined in an L27 orthogonal array. The 27 combinations established by the orthogonal array were simulated in SymufactWelding@ software. After all, combinations were simulated, carried out the data treatment, reaching the combination of levels for each parameter, which minimizes the level of residual stresses, as well as the most influential parameter in its appearing.

In the work presented in this section, it was analyzed the influence of the essential welding parameters on the residual stress amplitude in the welding corner joint. For this, it was developed a Taguchi orthogonal array of tests, L27, where it is possible to combine different levels for the defined parameters. Table 1 shows the levels used for each parameter.

Table 1. Welding parameters and levels.

\begin{tabular}{l|l|l|l|l|l}
\hline Number & Parameters & Units & \multicolumn{4}{|l}{ Levels } \\
\cline { 4 - 6 } & & & 1 & 2 & 3 \\
\hline 1 & $\begin{array}{l}\text { Welding } \\
\text { current }\end{array}$ & A & 163 & 181 & 202 \\
\hline 2 & $\begin{array}{l}\text { Welding travel } \\
\text { speed }\end{array}$ & $\mathrm{mm} / \mathrm{s}$ & 10 & 13 & 16 \\
\hline 3 & Torch angle & 0 & $30^{\circ}$ & $45^{\circ}$ & $60^{\circ}$ \\
\hline
\end{tabular}

Based on the combination of parameters and levels defined by L27 array, were implemented 27 simulations with the SymufactWelding@ software, which uses the numeric model of double ellipsoid for distribution of energy transferred by the heat source to the 
part. The previously experimental specimen (Fig. 1) calibrated the dual ellipsoid model and transversal section cord, which, in this case, was used as a robot. This measurement was performed with metallographic samples of the welding cord.

After all simulations completed, the values of the maximum principal stress (MaxPS) were withdrawn at various points along the $\mathrm{x}$-axis, Fig. 2.

In each simulation are determined the maximum values of residual stresses. Analyzing the obtained results was established by the combination that gives the less amount of residual stresses. So, for MaxPS combination which minimizes the residual stress is the welding current of $202 \mathrm{~A}$, welding speed of $10 \mathrm{~mm} / \mathrm{s}$ and a torch angle with $30^{\circ}$, on the contrary combination that maximize residual stress is the welding current of $163 \mathrm{~A}$, welding speed of $16 \mathrm{~mm} / \mathrm{s}$ and a torch angle with $60^{\circ}$. This data will be used as preliminary parameters in the experimental procedures.

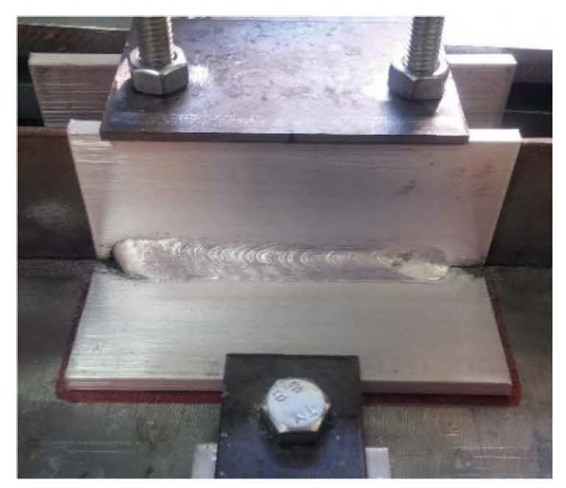

Fig. 1. Experimental specimen of a corner joint.

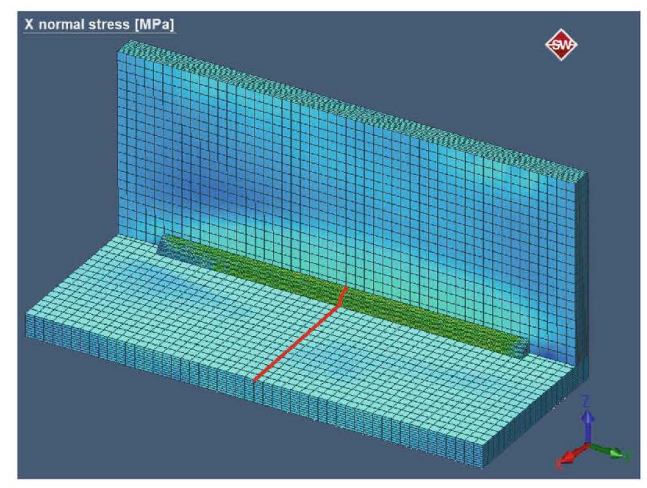

Fig. 2. Line of reading of the MPS computed.

\section{Experimental Procedures}

Experimental methods are usually performed in controlled laboratory settings [26], although they can also be implemented in the field [27]. In the work developed within the 
scope of this project, experimental tests were carried out in a laboratory with a controlled environment, which consisted of a robot with a welding apparatus and a fixation system for the parts (gig or gabarit). In addition to this base structure, it was used macrography equipment to analyze the weld beads [28] and apparatus for dimensional control to measure distortions [29]. During this study, it was measured the residual stresses using the incremental hole method [30] or the contour method [31], and the internal defects were controlled with ultrasound [32]. Some mechanical properties of the welding were also determined [33], namely, the yield strength, the tensile strength, and the elongation. A significant part of the quality control elements of the welds is based on the ASME IX standard [34]. The experimental tests allowed us to determine the optimal welding parameters for obtaining good quality welds, in this sense and to reduce the number of tests, it was decided to use an optimization method widely used in quality control in the industry, called the Taguchi method [35, 36]. This method allows the definition of experimental test plans, where various combinations of welding parameters are indicated. Between these combinations, it is possible to obtain the optimum value for a given control characteristic. The advantages of this method have popularized it in the definition of experimental test plans in various manufacturing processes [37, 38], namely, in welding $[39,40]$.

Before implementing the experimental tests, several Taguchi orthogonal arrays were created with different combinations of control factors and levels. For this purpose, eight factors were chosen (current intensity, travel speed, electrode wire speed, type of transfer, welding sequence, thickness of base material, base material and addition material) and the levels varied between 2 and 4 and were chosen, in a first phase, according to the database obtained in the numerical simulations.

The experimental tests focused, primarily, on the welding of tubular hyperstatic triangular structures, very common in bicycle frames. Figure 3 shows the type of hyperstatic triangular structure used in this project.

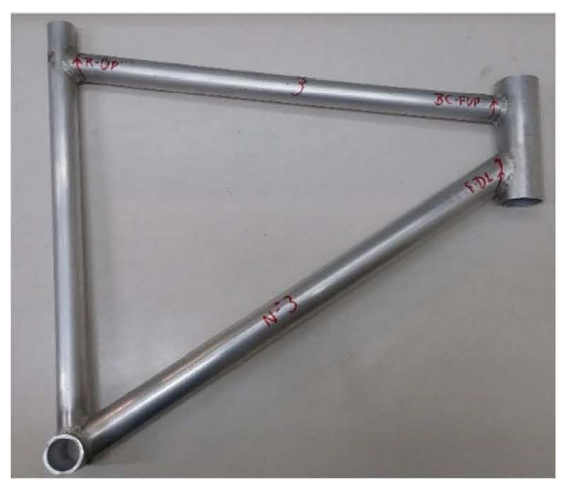

Fig. 3. Welded tubular hyperstatic triangular structure.

The selected aluminum alloy was the 6061-T6 alloy, which is the most common in the manufacture of bicycles. To carry out the experimental tests it was necessary to design and manufacture a system (gig or gabarit) that would guarantee, with high 
accuracy and repeatability, the positioning and fixation of the tubes to be welded. The tubes were always placed in the same position on the gig that is attached to a positioner. Several programs were carried out, according to the previously defined test arrays. After the first set of tests, it was found that some levels of parameters used resulted in a very high level of defects and that they were observed visually. In other cases, it was proved, in macrographic exams, that there were defects of incomplete penetration and undercut. This first evaluation made it possible to select new levels of parameters. The experimental tests were repeated, iteratively, to determine the optimal combination, in Fig. 4, it is possible to observe the assembly used in one of the welding tests performed. During the period of the experimental trials, more than two hundred welding tests were carried out (tubular triangles). As a result of these tests, some frames showed visible defects, that invalidated them immediately. In contrast, others were subjected to a set of destructive and non-destructive tests, defined by the standards mentioned above.

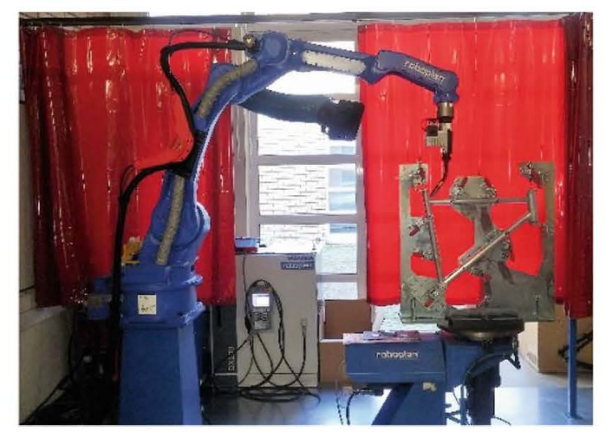

Fig. 4. The set-up used in the experimental tests of welding.

Non-destructive tests were carried out with ultrasound technology. The ultrasound device uses the "phase array" method, this new method allows a more global and accurate assessment in the detection of internal defects. Thus, a high number of welded joints was analyzed with this technology, and it determined that some of them contained pores inside and incomplete fusion, the frames that provided these defects were also rejected and evaluated, in greater detail, with macrographic techniques. Some of the pictures that did not present internal defects were also subjected to macrographic analysis to assess the geometry of the cord.

The destructive tests were performed to determine some mechanical properties of the welded joints and to assess the geometry of the bead or the occurrence of internal defects. This classification also includes the technique used to measure residual stresses, with the incremental hole method. For the mechanical characterization, the dimensions and geometry of the welded specimens follow the ISO 4136. The tensile strength of the joint was determined, as well as the location of the fracture. The test pieces were welded with the welding parameters of the frames that did not present unacceptable defects.

The macrographic tests were carried out on welded joints of frames with defects detected in the ultrasound exams. The macrographic tests allowed to evaluate the geometry of joints, as well as, to observe and measure the heat-affected zone. It is possible, 
also, to observe the most important detects like porosity, incomplete fusion and penetration, solidification structure, segregations, and, in some cases, it was possible to observe cracks after cooling. Figure 5 shows a macrographic image of one of the analysed welded joints.

Another factor that was analyzed to assess the quality of welded joints was residual stress. For the measurement of residual stresses, a classic method was used, which is widely used in industrial and academic environments, called the incremental holedrilling. For this method is used a special rosette of electric strain gauges in the center of which a small hole (diameter 0.6-1.8 $\mathrm{mm}$ ) is made up to $1 \mathrm{~mm}$ deep, with an increment of $0.1 \mathrm{~mm}$. The incremental hole-drilling method allows measuring with high resolution and accuracy the residual stresses installed in the welded joint. The measurements of residual stresses happened in welded joints without defects detected by the previously described techniques, and it found that the value of residual stresses lies between $30 \%$ to $60 \%$ of the yield stress of the base material.

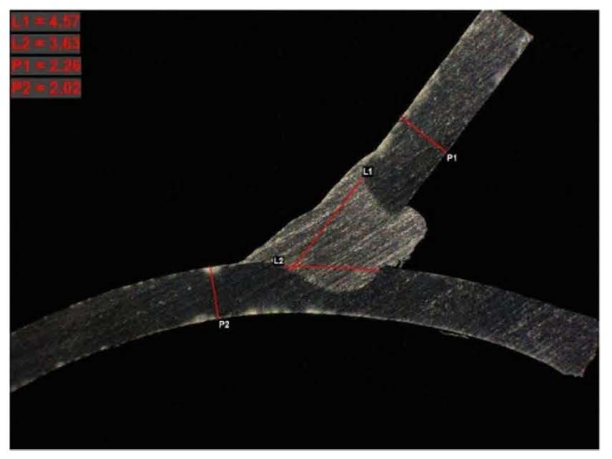

Fig. 5. Macrography of one of the joints analyzed in this work.

In addition to the evaluation of welded joints mechanical characteristics, the bead geometry and defects, and the level of residual stresses, it was also measured the distortions that occurred in the frame after welding and its removal from the gig. The distortion measurement was performed using a C-Track stereoscopic vision device, which uses the Metrolog Software, using the HandyProbe to capture control points.

The statistical treatment was carried out using the technique of analysis of variance (ANOVA), in this report will be presented some results related to control factors more relevant to obtain quality welding. After several welding tests and analysis of results, it was found that the most critical welding parameters were the addition material (A), the current intensity (B), the thickness of the base material (C), the travel speed (D), and the speed of the electrode wire (E). For most welding parameters, three levels were considered, except for the addition material and, as mentioned above, only the two most suitable materials for welding 6061-T6 alloy. Considering the referred parameters and levels, the most appropriate Taguchi array is L18.

After conducting the 18 tests (welding 18 frames), was carried out the quality control described above. Subsequently evaluating the results, was used the ANOVA technique to determine which parameters were most influential for each of the control factors 
evaluated. This scientific article will present the analysis of variance for the most relevant control factor, which is distortion. Table 2 shows the ANOVA analysis for maximum distortion.

Observing the Table 2 is possible to claim that the travel speed is the most influential welding parameter $(29.46 \%)$ for the frame distortion follow by the addition material (20.44\%). The least influential parameter is the current intensity with a contribution of $2.22 \%$.

Table 2. ANOVA analysis for maximum distortion.

\begin{tabular}{l|r|r|r|l|l}
\hline Source & DF & \multicolumn{1}{l|}{ SQ } & \multicolumn{1}{l|}{ MS } & F-Value & Contribution (\%) \\
\hline A & 1 & 33.135 & 33.135 & 7.89 & 20.44 \\
\hline B & 2 & 3.607 & 1.804 & 0.43 & 2.22 \\
\hline C & 2 & 27.110 & 13.555 & 3.23 & 16.72 \\
\hline D & 2 & 47.764 & 23.882 & 5.69 & 29.46 \\
\hline E & 2 & 16.92 & 8.460 & 2.01 & 10.44 \\
\hline Error & 8 & 33.595 & 4.199 & & 20.72 \\
\hline Total & 17 & 162.131 & & & \\
\hline
\end{tabular}

\section{Conclusions}

The presented work has implemented a methodology applied to automate with a robotic welding cell to weld hyperstatic bicycle frame of aluminum alloy.

This methodology involved two phases, where the first step involved numerical simulations to minimize the distortion and residual stresses. Using this data as preliminary parameters were implemented in the experimental tests.

For the numerical simulations was used the SymufactWelding@ software to simulate the welding process in which the parameters were chosen after the implementation of the Taguchi method. It was simulated 27 combinations of welding parameters and levels.

In the experimental procedures, a robotic welding cell was assembled to test different welding parameters to obtain a hyperstatic frame in aluminum alloy. The first values of welding parameters used in the experimental tests were based on the numerical simulations. The experimental procedure also used the optimization method of Taguchi, and the ASME IX standard indicated the quality parameters. So, were implemented destructive and non-destructive tests to qualify the quality of the welding frames. It was possible to obtain welding aluminum frames with acceptable quality in agreement with the ASME IX standard.

Acknowledgements. The authors are grateful to the Foundation for Science and Technology (FCT, Portugal) for financial support by national funds FCT/MCTES to CIMO (UIDB/00690/2020). 


\section{References}

1. Demirdöven, N., Deutch, J.: Hybrid cars now, fuel cell cars later. Science 305(5686), 974-976 (2004)

2. Williamson, S., Emadi, A., Rajashekara, K.: Comprehensive efficiency modeling of electric traction motor drives for hybrid electric vehicle propulsion applications. IEEE Trans. Vehicular Technol. 56(4), 1561-1572 (2007)

3. Ghassemieh, E.: New Trends and Developments in Automotive Industry. InTech, Rijeka (2011)

4. Chawla, N., Chawla, K.: Metal-matrix composites in ground transportation. J. Minerals, Metals Mater. Soc. 58(11), 67-70 (2006)

5. Carle, D., Blount, G.: The suitability of aluminium as an alternative material for car bodies. Mater. Des. 20, 267-272 (1999)

6. Banhart, J.: Aluminium foams for lighter vehicles. Int. J. Vehicle Des. 37(2-3), 114-125 (2005)

7. Aluminium in transport. European Aluminium Association Report (2014)

8. Lin, C., Huang, S., Liu, C.: Structural analysis and optimization of bicycle frame designs. Adv. Mech. Eng. 9(12), 1-10 (2017)

9. IBF. http://www.ibike.org/library/statistics-data.htm. Accessed 27 Jan 2020

10. Toros, S., Ozturk, F., Kacar, I.: Review of warm forming of aluminum-magnesium alloys. J. Mater. Process. Technol. 207(1-3), 1-12 (2008)

11. Lakshminarayanan, A.K., Balasubramanian, V., Elangovan, K.: Effect of welding processes on tensile properties of AA6061 aluminium alloy joints. Int. J. Adv. Manuf. Technol. 40, 286-296 (2007). https://doi.org/10.1007/s00170-007-1325-0

12. Malarvizhi, S., Balasubramania, V.: Effect of welding processes on AA2219 aluminium alloy joint properties. Trans. Nonferrous Metals Soc. China 21(5), 962-973 (2011)

13. Avalle, M., Belingardi, G., Cavatorta, M., Doglione, R.: Casting defects and fatigue strength of a die cast aluminium alloy: a comparison between standard specimens and production components. Int. J. Fatigue 24(1), 1-9 (2002)

14. Barnes, T., Pashby, I.: Joining techniques for aluminium spaceframes used in automobiles Part I - solid and liquid phase welding. J. Mater. Process. Technol. 99, 62-71 (2000)

15. Maddox, S.: Review of fatigue assessment procedures for welded aluminium structures. Int. J. Fatigue 25(12), 1359-1378 (2003)

16. James, F., et al.: Residual stresses and fatigue performance. Eng. Failure Anal. 14(2), 384-395 (2007)

17. Gourd, L.: Fundamentals of Welding - Principles of Welding Technology, 3rd edn. Butterworth-Heinemann, Paris (1995)

18. Teng, T., Fung, C., Chang, P., Yang, W.: Analysis of residual stresses and distortions in T-joint fillet welds. Int. J. Pressure Vessels Piping 78(8), 523-538 (2001)

19. Teng, T., Chang, P., Tseng, W.: Effect of welding sequences on residual stresses. Comput. Struct. 81(5), 273-286 (2003)

20. Umbrello, D.: Finite element simulation of conventional and high-speed machining of Ti6Al4V alloy. J. Mater. Process. Technol. 196(1-3), 79-87 (2008)

21. Lewis, R., Ravindran, K.: Finite element simulation of metal casting. Int. J. Numerical Methods Eng. 47(1-3), 29-59 (2000)

22. Guo, L., Yang, H., Zhan, M.: Research on plastic deformation behaviour in cold ring rolling by FEM numerical simulation. Modell. Simulat. Mater. Sci. Eng. 3(7), 1029-1046 (2005)

23. Deng, D., Murakawa, H., Liang, W.: Numerical simulation of welding distortion in large structures. Comput. Methods Appl. Mech. Eng. 196(45-48), 4613-4627 (2007) 
24. Zeng, Z., Wang, L., Du, P., Li, X.: Determination of welding stress and distortion in discontinuous welding by means of numerical simulation and comparison with experimental measurements. Computat. Mater. Sci. 49, 535-543 (2010)

25. Toyoda, M., Mochizuki, M.: Control of mechanical properties in structural steel welds by numerical simulation of coupling among temperature, microstructure, and macro-mechanics. Sci. Technol. Adv. Mater. 5(1-2), 255-266 (2004)

26. Janosch, J.: International institute of welding work on residual stress and its application to industry. Int. J. Pressure Vessels Piping 85(3), 183-190 (2008)

27. Assunção, E., Quintino, L., Miranda, P.: Comparative study of laser welding in tailor blanks for the automotive industry. Int. J. Adv. Manuf. Technol. 49(1-4), 123-131 (2010)

28. Peel, M., Steuwer, A., Preuss, M., Withers, P.: Microstructure, mechanical properties and residual stresses as a function of welding speed in aluminium AA5083 friction stir welds. Acta Mater. 51(16), 4791-4801 (2003)

29. Sattari-Far, I., Javadi, Y.: Influence of welding sequence on welding distortions in pipes. Int. J. Pressure Vessels Piping 85(4), 265-274 (2008)

30. Ribeiro, J., Monteiro, J., Lopes, H., Vaz, M.: Moiré interferometry assessement of residual stress variation in depth on a shot peened surface. Strain 47(S1), e542-e555 (2011)

31. Richter-Trummer, V., Moreira, P., Ribeiro, J., Castro, P.: Moiré Interferometry The contour method for residual stress determination applied to an AA6082-T6 friction stir butt weld. Mater. Sci. Forum 681, 177-181 (2011)

32. Arone, M., Cerniglia, D., Nigrelli, V.: Defect characterization in Al welded joints by noncontact Lamb wave technique. J. Mater. Process. Technol. 176(1-3), 95-101 (2006)

33. Kumar, A., Sundarrajan, S.: Optimization of pulsed TIG welding process parameters on mechanical properties of AA 5456 Aluminum alloy weldments. Mater. Des. 30(4), 1288-1297 (2009)

34. Part QW Welding - Welding General Requirements. ASME IX (2013)

35. Ross, P.: Taguchi Techniques for Quality Engineering, 2nd edn. McGraw-Hill, New York (1988)

36. Wu, Y., Wu, A.: Taguchi Methods for Robust Design. American Society of Mechanical Engineers, New York (2000)

37. Ribeiro, J., César, M.B., Lopes, H.: Optimization of machining parameters to improve the surface quality. Procedia Struct. Integrity 5, 355-362 (2017)

38. Syrcos, G.: Die casting process optimization using Taguchi methods. J. Mater. Process. Technol. 135(2), 68-74 (2003)

39. Sapakal, S., Telsang, M.: Parametric optimization of MIG welding using taguchi design method. Int. J. Adv. Eng. Res. Stud. 1(4), 28-30 (2012)

40. Pal, S., Malviya, S., Pal, S., Samantaray, A.: Optimization of quality characteristics parameters in a pulsed metal inert gas welding process using grey-based Taguchi method. Int. J. Adv. Manuf. Technol. 44(11-12), 1250-1260 (2009) 